\title{
Artelogie
}

Recherche sur les arts, le patrimoine et la littérature de l'Amérique latine

1 | 2011

Brésil, questions sur le modernisme

\section{Introdução : Questões do modernismo brasileiro}

Monica Pimenta Velloso

\section{OpenEdition}

\section{Journals}

\section{Edição electrónica}

URL: https://journals.openedition.org/artelogie/8247

DOI: 10.4000/artelogie.8247

ISSN: 2115-6395

\section{Editora}

Association ESCAL

\section{Refêrencia eletrónica}

Monica Pimenta Velloso, «Introdução : Questões do modernismo brasileiro», Artelogie [Online], 1 |

2011, posto online no dia 01 março 2011, consultado o 07 janeiro 2022. URL: http://

journals.openedition.org/artelogie/8247 ; DOI: https://doi.org/10.4000/artelogie.8247

Este documento foi criado de forma automática no dia 7 janeiro 2022.

Association ESCAL 


\title{
Introdução : Questões do modernismo brasileiro
}

\author{
Monica Pimenta Velloso
}

1 A historiografia sobre o modernismo no Brasil, como no conjunto dos paises latinoamericanos, vem demandando novos enfoques, redefinições teórico metodológicas e conceituais em função das próprias mudanças que marcaram o cenário contemporâneo da pós modernidade. $O$ redirecionamento das indagações de pesquisa demanda um diálogo intercontinental.

Refletir sobre o fenômeno modernista no Brasil implica antes de tudo em analisar a natureza dos vínculos estabelecidos com o paradigma civilizatório europeu.

3 Na virada do século XIX, contexto de franca aceleração das mudanças científicotecnológicas, o par antigo/moderno, uma das bases de inteligibilidade da cultura ocidental, integrou novos sentidos e combinações. Jacques Le Goff nos lembra que historicamente coube aos indivíduos, às sociedades e às épocas o trabalho de definir o moderno perante o passado. Compreendê-lo na sua inquietante mutabilidade adequando-o ao acervo milenar das tradições negras, indígenas e mestiças foi desafio enfrentado pelos intelectuais latino americanos.

4 O que estava em questão era a reconfiguração da tradição artística ocidental e o redirecionamento da imaginação.

5 Como essa "moderna tradição" foi encampada em terras brasileiras ? Como foi percorrido o campo das tensões ? interessa analisar, enfim, como as idéias foram experimentadas, decodificadas e integradas passando a forjar novas inteligibilidades, sensibilidades e configurações culturais. Polissêmica, multifacetada e extremamente dinâmica na sua capacidade de articular e combinar valores, a brasilidade modernista marca-se pela confluência de distintas tradições e temporalidades.

6 Essa é uma das questões que se coloca em primeiro plano quando se propõe repensar o modernismo brasileiro à luz da atualidade.

7 Repensar a "tradição da ruptura", como observa Otavio Paz, implica em repensar o tempo, história, ética e poética. 
8 Ainda hoje desfruta de certa aceitação a visão historiográfica que relaciona, mesmo que sub-repticiamente, o modernismo à ambiência paulista (ou às capitais culturais) limitando o movimento a um grupo de intelectuais e obras canônicas. Não é demais lembrar o caráter comprometedor dessa abordagem perdendo-se de vista a densidade histórica do fenômeno e seus desdobramentos e implicações concretos na vida cotidiana e mundializada.

O Modernismo abrigou um conjunto complexo de transformações que ocorreram no campo das artes entre a década de 1870 e o inicio da Segunda Guerra mundial, envolvendo toda a Europa, Estados Unidos e países latinos americanos.

10 Na historiografia modernista brasileira a crítica ao paradigma de 1922 começou a ser elaborada no início da década 1980, com o surgimento de novos estudos na área da história, literatura, arte e filosofia. Nesta época, a nova história cultural aperfeiçoando os seus instrumentais teóricos possibilitava uma re-conceituação da cultura, do passado, da memória e da própria temporalidade histórica. Esses fatores abriram um novo campo de indagações refinando e tornando mais complexo o entendimento sobre as nacionalidades, notadamente, em momentos em que se estreitavam os seus laços de convívio.

11 Na vida cultural brasileira, a sociedade urbana, industrial e tecnológica foi capaz de conviver com o sertão e o arcaico. A bossa e a palhoça, Ipanena e Iracema, como sintetizou a canção de Caetano Velloso no movimento tropicalista na década de 1970.

12 As tensões, reações e ambivalências que acompanharam a construção de uma estética da brasilidade modernista serão matéria de estudo desse dossiê.

13 Explorando os vários domínios artísticos, dentre os quais, literatura, teatro, cinema, artes plásticas (pintura, gravura, arquitetura, escultura) e integrando temas referentes à linguagem corporal, os trabalhos aqui incluídos revelam cuidado dispensado à atividade da recepção e reajuste de idéias.

14 Mostra-se que os sinais de modernidade se expandiram muito além do Rio de Janeiro e de São Paulo, mobilizando a atenção dos intelectuais bem antes da realização da Semana de Arte moderna de 1922. Foram nos jornais de Natal e de Salvador, através de Manuel de Sousa Dantas e Almanáquio Diniz que se registraram os primeiros debates sobre o futurismo, imediatamente após o lançamento do Manifesto de Marinetti, em fevereiro de 1909. o futurismo foi interpretado no Brasil como uma estética patológica e anarquizante. Mas ao mesmo tempo avaliava-se que era uma "operação higiênica" necessária abrindo espaço para uma nova ordem literária garantindo-se o lugar da cultura latina na ordem civilizacional.

15 No imaginário social brasileiro, as conquistas futuristas ganharam inteligibilidade no jogo vivo das tradições.

16 A linguagem cinematográfica da velocidade, do simultaneísmo e do deslocamento espaço-temporal tão prezada nas páginas da Klaxon, revista vanguardista de São Paulo, conviveu com ideais de modernidade pautados pela lógica da verossimilhança. Considerar a ambigüidade da recepção oscilando entre acolhimento/recusa sempre mediados pelo crivo da adequação é um caminho que possibilita entender mais a fundo a historicidade do processo.

17 Um outro tema contemplado pela Artelogie e que muito ajuda a entender as especificidades do moderno brasileiro é a distinta inserção dos intelectuais. Se Lima Barreto e Mário de Andrade configuram experiências de vida e obra extremamente 
distintas em função do próprio momento e lugar que ocupavam no campo intelectual, ambos estavam visceralmente empenhados na formação de uma nova consciência social e estética. De um lado, a cidade capital do Rio de Janeiro na virada do século XIX, de outro, São Paulo nas décadas de 1920 e 1940. Uma sensibilidade marcada pela exclusão social e a outra pelas exigências vanguardistas.

De maneiras distintas esses autores vincularam-se à moderna tradição que, se rebelando contra os limites da ordem cientifico burguesa, gerava uma nova sensibilidade. A vida social deixava de ser concebida como algo exterior e consensual, transformando-se em objeto de indagações, mas também em fonte de angústias. Escritas de si simbolizavam questões de um espectro mais complexo remetendo à constituição da própria nacionalidade.

Barreto abria espaço para um outro entendimento do fenômeno modernista brasileiro ao conjugar tradições do romance realista de finais do século XIX com tradições cômicas das culturas populares. $O$ autor conseguiu criar uma escrita avant la lettre desnudando o aspecto compósito e conflituoso da cultura brasileira. Já Mário de Andrade dramatizou com intensidade o ofício da escrita em função dos compromissos que julgava ter com a construção do projeto estético da brasilidade. Se identificava a subjetividade e a intuição ensaística como matéria reflexiva, alertava, no entanto, para o caráter primordial da técnica literária.

Definir estratégias textuais frente à questão do engajamento foi questão polêmica, mobilizando o debate modernista.

21 Sérgio Buarque de Holanda e Prudente de Mores Netto, ao longo da década de 1920, polemizam sobre a questão. Discordando da ênfase atribuída ao construtivismo que reforçava a necessidade de uma conceituação sobre o moderno propunha-se a perspectiva experimental, entendendo-a como mediação necessária para uma reflexão sobre a brasilidade. Analisar as dissidências internas na estética modernista é procedimento importante ajudando a desfazer o cânone construtivista.

Os estudos desse dossiê também mostram a necessidade de reavaliar a atuação das vanguardas, chamando atenção para a historicidade da vida cotidiana. Não só italianos, franceses e alemães constituíram-se em força inovadora inspirando a brasilidade modernista. Portugueses também tiveram seu lugar. Se houve forte reação a essa influência, sendo o grupo constantemente identificado com a experiência da colonização e do atraso cultural, , tais idéias não obtiveram total consenso. Na constituição da moderna dramaturgia é necessário considerar fatores de ordem material e pragmática, como a precariedade de recursos e de pessoal especializado. Também exerceu influência decisiva o fenômeno da imigração. No Rio de Janeiro, por exemplo, a tradição associativa dos portugueses lhes possibilitou impulsionar as atividades culturais e teatrais.

Dentre as várias propostas de uma dramaturgia nacional, no início do século XX, havia uma que apoiava a atuação de grupos e empresários lusitanos. Essa configuração de um "Rio de Janeiro lusitano" possibilitava o estreitamento de contatos com a Europa, favorecendo a cooperação entre os dois lados do Atlântico. Mas o projeto acabou sendo abortado devido à reorientação nacionalista do movimento após 1924.

Essa disputa pela eleição de uma dramaturgia brasileira adquire outras configurações no nordeste. No Recife, entre as décadas de 1950-70, a polêmica sobre as peças de Ariano Suassuna mapeia conflitos político simbólicos entre as elites paraibanas e 
pernambucanas. No entanto, o confronto entre valores urbanos/cosmopolitas e agrários/regionais, não incide sobre o moderno, desfazendo-se sua suposta incompatibilidade com o regionalismo. Narrativas da literatura de cordel, personagens do Teatro de Mamulengo, tradições orais sertanejas revelam a heterogeneidade das referências culturais.

Essa é uma outra questão obrigatória na pauta de discussão do modernismo brasileiro. A capacidade de construir novas inteligibilidades articuladoras ampliando-se o patamar do moderno brasileiro. Freqüentemente, o regional apresentou-se como mediação da singularidade cultural, colocando em questão um projeto de modernidade baseado na hegemonia do progresso e da razão cientifico tecnológica.

Desde que foi reavaliado o entendimento do modernismo valorando-se o diálogo estabelecido com as tradições, a questão da participação intelectual também passou por um reexame historiográfico.

Mediação e sociabilidade, assim também como outras categorias oriundas da história da leitura e do fenômeno da circulação de culturas, compuseram instrumental importante de análise ajudando a redimensionar a participação intelectual. o próprio exercício da escrita passou pelo crivo analítico.

Esse conjunto de questões possibilitou lançar um novo olhar sobre a obra de Paulo Prado avaliando-se os fatores de seu impacto na época. É possível pensar que um dos seus maiores méritos resida no fato de ter conseguido acionar e dar sistematicidade a "repertórios disponíveis" de idéias. Erudito e competente mediador entre distintas gerações e mentalidades, este intelectual assegurou a continuidade de idéias, estreitando sociabilidades simbólicas entre as elites paulistas e parisienses.

Esse exercício de adequar tradições à modernidade foi operacionalizado de distintas maneiras em função das questões que estavam sendo colocadas em pauta pela agenda internacional das idéias.

30 O tema do primitivismo gerou múltiplas apropriações no bojo das quais surgiram as invenções míticas do Brasil e dos brasileiros, obra conjunta de europeus e brasileiros.

31 Mas o solo dessas utopias é distinto, originando configurações especificas. Enquanto a Europa atravessava uma fase de esgotamento da cultura projetando no continente americano as suas utopias civilizadoras (e desejos de exotismo), o Brasil e os países latino-americanos efetuavam movimento inverso, mergulhando no passado em busca de raízes. Esse aspecto da brasilidade como construção conjunta marcada pelo atravessamento de distintas temporalidades é contemplado pelos estudos Artelogie que o explora nas suas diferentes linguagens artísticas, dentre elas, a literatura, o ensaismo sociológico e a pintura.

Freqüentemente o continente americano converteu-se no pólo de aprendizagem. Identificava-se o Brasil e o conjunto do continente americano como espaço gerador de uma nova ordem poética, capaz de renovar a crítica literária e a história. Blaise Cendrars avaliava que a integração à paisagem brasileira e às raízes primitivas da sua cultura lhe possibilitaram acesso à renovação, viabilizando a profissão de escritor.

33 A aceleração do fenômeno da mundialização alterava a própria hierarquia e o deslocamento dos fluxos culturais. Viagens etnográficas, movimentos de imigração, guerras e também a realização de eventos culturais de âmbito internacional afetaram sensivelmente os modos de pensar as identidades nacionais. 
34 A realização da Copa de futebol em 1938 na França é um exemplo desse processo de reavaliação. O fato de o Brasil apresentar uma equipe que mesclava jogadores de origem negra e branca incentivou a invenção de uma brasilidade mestiça. Se a polêmica em torno deste esporte já vinha mobilizando a atenção dos intelectuais modernistas, depois da sua internacionalização a discussão ganhou outros rumos. Deixando de ser visto apenas como "subproduto de importação" limitado à matriz européia, o futebol passara a contribuir diretamente na invenção de um corpo brasileiro. Articulava-se música, futebol e etnia. Coube a Gilberto Freyre, na década de 1940, sistematizar essa interpretação da brasilidade. pulares presentes nos continentes africano, asiático e americano. Também o primitivismo incluía expressões das culturas urbanas populares e contemporâneas tais como o circo, o folhetim e as danças. Este acervo etnográfico, aliado à teoria de Lévy-Bruhl sobre as mentalidades pré lógicas, constituía-se em uma das bases inspiradoras da moderna estética. Intensificando a circulação de pessoas e de idéias, este clima de efervescencia cultural gerou práticas artísticas oriundas de um espaço inédito : o "entre-mundos". Não se tratava de configurar objetos no território, mas em horizontes planetários, de acordo com Serge Gruzinski.

A discussão dessa especificidade hermenêutica está presente no dossiê e é trazida ao debate através da questão do corpo. Para os europeus, o corpo converte-se em lugar de projeção das utopias liberadoras ; em relação aos brasileiros se converte em memórias de infância ou dos antepassados. de estudos de gestualidades corporais presentes nos acervos pictóricos europeus, latino-americanos e brasileiros. Através do diálogo entre essas tradições e as experiências de deslocamento da artista integrando paisagens urbanas e rurais, referências cosmopolitas, nacionais, regionais e locais, o corpo de "A Negra" (1923) sugere novos caminhos para o entendimento do imaginário pictórico modernista, iluminado as interpretações da atualidade.

41 Uma outra questão estratégia nos estudos do modernismo é a que se refere à dinâmica que preside a trama das tradições. Esta sempre se impôs como operação reflexiva tanto para atores que viveram a época como para os historiadores que a tomam como objeto de estudo e investigação. No curso da vida social as tradições são incessantemente deslocadas e remanejadas, procedendo-se à atualização de seus significados. Este ato de presentificação implica, portanto, em uma absorção criteriosa e seletiva das idéias. 
42 Na modernidade arquitetônica brasileira, conforme mostra a Artelogie, ganhou atenção o ideal comunitário que privilegiava o espaço público urbano como lugar do convívio, filtrado pela subjetividade das relações. Foram tais ideais, baseados no manifesto "Nine Points on Monumentaly" (1943) que inspiram a arquitetura de Lúcio Costa e a própria construção de Brasília, obra síntese da modernidade. A proposta de uma arte capaz de entrosar os seus diversos domínios e linguagens, abolindo-se as distinções hierárquicas entre arte e artesanato, encontrou no Brasil solo receptivo. Formas comunitárias de convívio e do fazer artístico faziam parte do cotidiano cultural brasileiro predispondo-o à assimilação de múltiplos processos artísticos. Articulando o local ao universal, os modernistas, de acordo com Antonio Candido, conseguiriam reencontrar a influência européia por um mergulho no detalhe brasileiro.

43 A mundialização das trocas culturais implica no processo de re-simbolização de valores que se transformam em outras significações constituindo-se as bases de uma nova estética. A obra paisagística de Burle Marx que trabalhou junto à equipe de Lucio Costa durante o Estado Novo (1937-45), destaca-se como exemplo dessa transfiguração criadora, abrindo-se a uma nova sensibilidade social.

o fato revela o caráter complexo da modernização brasileira. Se o governo Vargas incentivava a reflexão e a pesquisa apoiando realizações inovadoras dos intelectuais reunidos em torno do Ministério Capanema, exercia, ao mesmo tempo, rígido controle sobre os meios de comunicação através do Departamento de Imprensa e Propaganda (DIP). Na realidade, controle e liberdade criadora se mesclavam na vida social brasileira.

É neste contexto marcado pelas ambivalências que se desenvolvem projetos arquitetônicos e idéias profundamente arrojados. Projetado por Oscar Niemayer com painéis de Cândido Portinari e jardins de Burle Marx, o prédio do Ministério da Educação foi considerado um dos marcos da moderna arquitetura brasileira. Inspirando-se nos ensinamentos de Bauhaus, kandinsky e Fernand Léger, Burle Marx inaugurou uma nova concepção da arte paisagística latino-americana suplantando a modernidade formal do inicio do século. $O$ artista fez do seu sitio espaço do experimento ao concebê-lo como um microcosmo da brasilidade integrado pela flora, clima e geologia Nesta experiência privilegiara não a pesquisa de formas mas a lógica da ecologia despertando atenção para uma nova potencialidade estética.

Essa proposta de pesquisar, preservar, e combinar novos materiais em sintonia com a memória e identidades nacionais enriqueceu sobremaneira a estética modernista brasileira.

Dentro deste quadro marcado por articulações tão múltiplas e complexas ainda permanecem praticamente esquecidos pela historiografia modernista os laços entre o Brasil e o conjunto dos países latino americanos. Os desdobramentos do modernismo na vida social, ao longo das décadas de 1930 até 1960, possibilitam um reexame dessa situação. Garantindo um novo estatuto às artes, uma imprensa especializada e canais competentes na divulgação da produção artística nacional, as cidades do Rio de Janeiro, de São Paulo e a de Buenos Aires funcionaram em relação a alguns países latinoamericanos como pólos catalisadores e irradiadores da renovação artística. Mostrar a articulação entre esses pólos e outras cidades e países geralmente mantidos à margem da cartografia modernista também foi questão contemplada por esse dossiê. 


\section{RESUMOS}

Extrapolando os limites e marcos cronológicos, sensível aos novos espaços e modalidades participativas, mas, sobretudo, dispondo-se a re-configurar a natureza e o fluxo das trocas culturais, o modernismo brasileiro torna-se mais do que nunca tema polêmico em consonância com a efervescência de mudanças que se operam no horizonte social e historiográfico.

\section{ÍNDICE}

Palavras-chave: modernismo brasileiro, processos artísticos, cartografia modernista, referências cosmopolitas, nacionais, regionais

\section{AUTOR}

\section{MONICA PIMENTA VELLOSO}

Pós doutoramento na EHESS/Paris, historiadora e pesquisadora da Fundação Casa de Rui Barbosa e doCNPq 